\title{
Effect of Air Pollution on the Emergency Admissions of Cardiovascular and Respiratory Patients, Using the Air crossuark Quality Model: A Study in Tehran, 2005-2014
}

\author{
Majid Kermani ${ }^{1,2}$, Mohsen Dowlati ${ }^{*}$, Ahmad Jonidi Ja ' fari ${ }^{1,2}$, Roshanak Rezaei Kalantari ${ }^{1,2}$, Fazeleh Sadat Sakhaei ${ }^{3}$ \\ 1. Department of Environmental Health Engineering, School of Public Health, Iran University of Medical Sciences, Tehran, Iran. \\ 2. Research Center for Environmental Health Technology, Iran University of Medical Sciences, Tehran, Iran. \\ 3. Department of Nursing, Faculty of Nursing and Midwifery, Iran University of Medical Sciences, Tehran, Iran.
}

Cttat On: Kermani M, Dowlati M, Jonidi Ja fari A, Rezaei Kalantari R, Sakhaei FS. Effect of air pollution on the emergency admissions of cardiovascular and respiratory patients, using the air quality model: A study in Tehran, 2005-2014. Health in Emergencies and Disasters Quarterly. 2016; 1(3):137-146. http://dx.crossref.org/10.15412/J.HDQ.09010304

of $:$ : http://dx.crossref.org/10.15412/J.HDQ.09010304

Article info:

Received: 18 Oct. 2015

Accepted: 30 Jan. 2016

\section{Keywords:}

Air pollution, Emergency admission, Heart diseases, Respiratory diseases, Particulate matter

\section{ABSTRACT}

Background: Air pollution is one of the most important factors threatening the health of citizens. It increases the prevalence of cardiovascular and respiratory diseases as well as emergency admissions to hospitals in the polluted metropolitan cities. The present study was conducted using Air Quality (AirQ) model and aimed to investigate the effects of air pollution on the number of emergency cardiovascular and respiratory patients admissions in Tehran hospitals during 2005-2014.

Materials and Methods: This was cross-sectional study. First, the needed hourly information was received from the Bureau of Air Quality Control, and the Environmental Protection Agency of Tehran City. Then, the information was validated according to WHO criteria, and the statistical indicators and the stages required to quantify the harmful effects of air pollutants were calculated by using appropriate application.

Results: According to the results, the number of cases admitted to the emergency ward of hospitals due to heart diseases (by exposure to particulate matter) during the years 2005 to 2014 were respectively 1797, 1280, 1766, 1980, 2132, 2703, 2389, 2594, 2158, and 2291 cases, totaling 20990 persons, and for respiratory diseases (due to exposure to particulate matter) during the same years were respectively 4643, 3301, 4650, 5117, 5511, 6999, 6180, 6452,5577 , and 5922 cases, totaling 54352 people. Also, the number of cases admitted to the emergency wards of hospitals due to chronic obstructive pulmonary disease caused by exposure to emissions of pollutants such as sulfur dioxide, nitrogen dioxide, and ozone were respectively, 1806, 2454, and 2941 cases.

Conclusion: Air pollution in Tehran increases the load of emergency visits to hospitals and increases the risk of respiratory and heart diseases. Therefore, measures to reduce and control air pollution and to prepare, equip, and mobilize hospitals, particularly emergency wards, are among important priorities that should be pursued seriously by the authorities.

\footnotetext{
* Corresponding Author:

Mohsen Dowlati, MSc.

Address: Research Center for Environmental Health Technology, Iran University of Medical Sciences, Tehran, Iran

E-mail: mohsendowlati.69@gmail.com
} 


\section{Introduction}

ccording to WHO reports in 2014, seven million deaths are occurring annually due 1 to air pollution. This shows that air pollutants are associated with a high rate of mortality [1]. Air pollution is one of the most important environmental issues that its exposure causes several harmful effects, and given its growing trend in many large cities of the world, it threatens human health $[2,3]$. Tehran with more than 10 million population and home for many industries, along with its location, topography, and specific climate zone, is one of the most polluted cities in the world [4]. Air pollutants by penetrating human lungs induce or exacerbate respiratory illnesses such as emphysema and bronchitis. They can also exacerbate cardiovascular diseases and increase the number of cases admitted to hospitals and may also lead to early death [5].

In a study conducted by Dehghani et al. entitled "The Effects of Air Pollutants on Cardiorespiratory Patients Admitted to Selected Hospitals of the City of Shiraz" a significant correlation was found between the median carbon monoxide pollutants and cardiorespiratory patients admitted to studied hospitals [6]. Another study conducted by Younusian et al. in Tehran Heart Hospital entitled "The Relationship between Exposure to Air Pollution and the Onset of Acute Coronary Attacks Syndrome" employing the case-crossover design, showed a significant positive association between acute coronary syndrome and median 24-hour carbon monoxide as per the increase of each unit of carbon monoxide [7].

Another study by Goodini and colleagues entitled "The Relationship Between Concentration of Particulate Matter in the Air With the Number of Respiratory and Cardiac Patients Admitted to Hospitals in the City of Kermanshah in 2011" showed that the maximum and minimum numbers of admittance of respiratory patients had been, respectively, in the spring and winter seasons, and the maximum and the minimum numbers of admittance of cardiac patients were in the summer and autumn seasons. With regard to gender, male patients constituted the largest number of admitted patients. Connection between the number of admitted respiratory and cardiac patients with the existence of particulate matter in the air was statistically significant [8].

The problem of air pollution has attracted the political and scientific communities in the past decade and it seems that the damages of this phenomenon on human health are worthy of investigation. Tehran is one of the most polluted cities in the country and its level of air pollution increases each day in a way that conditions of life has become difficult and intolerable for many residents in this city. Therefore, it is expected that the number of patients admitted to the emergency wards of hospitals due to air pollution would increase in this city every year. Accordingly, there is a need for research in this area. Also, the authorities and experts should pay more attention in controlling air pollution. In addition, hospitals, especially emergency, cardiovascular, and respiratory wards should be prepared for admitting such patients. Hence, the present study was conducted with the aim of examining the effect of Tehran air pollution on the number of cardiovascular and respiratory emergency cases admitted to hospitals of Tehran during 2005-2014.

\section{Materials and Methods}

This study, conducted in the Greater Tehran metropolitan area, was a cross-sectional and descriptive study. We used AirQ 2.2.3 application to examine the effect of air pollution in Tehran on the number of cardiovascular and respiratory emergency admissions to hospitals. Hourly measurement of air pollutants was conducted by the Environmental Protection Agency and the Tehran Air Quality Control Institute through weather stations all over the city. The needed data were collected by referral to the mentioned organizations.

To determine the data validity for performing statistical analyzes, based on WHO criteria, the data recorded at weather stations were subjected to primary and secondary processing. In the primary processing, the exclusion of unnecessary data, sheet layout of the pollutants, and time standardization (to provide the median estimate) were performed and on the basis of WHO criteria, the number of weather stations with valid data were identified. In this regard, the ratio between the number of valid data for the 2 seasons (warm and cold season) should not be more than 2. Also, in order to achieve the median 24-hour values, at least $50 \%$ data must exist with sufficient validity.

For secondary processing in Excel, statistical indicators are needed, including annual average, warm season average, cold season average, and 98 percentile annual, the annual maximum, as well as the maximum values for warm and cold seasons of the pollutants. The population reported by Iran Statistics Center was considered as the population at risk of exposure to pollution. In the software, determination of the adverse health effects is related to the mass of the inhaled pollutant. Therefore, the input data should be in terms of weigh/volume units $\left(\mu \mathrm{g} / \mathrm{m}^{3}\right)$. For this purpose, by writing the program in Ex- 
cel and based on temperature and pressure conditions, the data were converted to proper units. For converting the unit of mass to unit of volume, the following general formula was used in which $\mathrm{P}$ represents air pressure, $\mathrm{T}$ represents temperature, and MW is molecular weight of the pollutants:

$$
\frac{\mu g}{m^{3}}=\frac{P(m m H g) \times M W \times p p m}{62.4 \times T\left({ }^{\circ} \mathrm{K}\right)} \times 100
$$

Attributable component or attributed ratio is a part of health outcome that is related to the exposure of specific population (assuming there is a possible association between exposures and health consequences without major confounding effect on this relationship) during a specified time period. This component is measurable using the following formula:

$$
A P=S U M\{[R R(c)-1] \times p(c)\} / S U M[R R(c) \times p(c)]
$$

Where RR(c): Relative risk of health consequence in group c or the target group, and $\mathrm{P}(\mathrm{c})$ : The ratio of group $\mathrm{c}$ or the target group. The relative risk (RR) of the selected health consequences can be obtained with the help of exposure-response functions.

By knowing the rate of incidence on the basis of the selected health consequences (I) in the target community, the amount attributed to population exposure (or the number of cases per population unit) (IE) can be calculated as follows:

$$
I E=I \times A P
$$

In a population with the size of $\mathrm{N}$, this rate can be converted to the number of estimated cases attributed to the exposure (NE):

$$
N \times N E=I E
$$

The user, instead of determining the quantity of incidence of the basis of health consequence, can use local statistics. As a result, the incidence of consequences in a population that is not faced with exposure (INE) can be estimated as follows:

$$
1 \times I N E=I-I E=(1-A P)
$$

In addition to all attributed cases, we can estimate the distribution of attributed cases in terms of the pollutant's concentration intervals. By knowing the relative risk at a particular level of the pollutant's concentration and the incidence of the illnesses in the unexposed population, the level of added incidence, $\mathrm{I}+(\mathrm{c})$, and the number of added cases, $\mathrm{N}+(\mathrm{c})$, in an exposed group c can be calculated through the following formula:

$$
I+(c) P(c) \times I N E=R R(c-1)
$$

All above formulas are based on the assumption that estimates used in this analysis have been controlled as regards to all possible confounding elements. By placing RR estimate confidence intervals in the formula, we can determine the low and high limits of AP estimate and the range of cases attributed to the expected exposure.

Eventually, by entering the processed data in AirQ, the results in the form of attributed component as regards to the number of emergency admissions to the hospitals of Tehran due to air pollution during the recent decade, were presented in the Tables 1-6.

\section{Results}

At first, after validation of data received from the Air Quality Control Institute and the Environmental Protection Organization, according to WHO criteria, the number of air stations in Tehran having valid data for analysis was identified. Of 11 stations in 2005, 14 stations in 2006, 14 stations in 2007, 15 stations in 2008, 18 stations in 2009, 37 stations in 2010, 36 stations in 2011, 42 stations in 2012, 35 stations in 2013, and 33 stations in $2014,10,10,11,11,11,19,15,33,11,29$ stations, respectively were valid for air quality index calculation and quantification of the health effects of air pollutants. After carrying out the analyses based on the results derived from AirQ, the number of additional cases and the component attributed to air pollutants were estimated for the total number of emergency admissions for hospitalization. For calculating the health effects and consequences through AirQ, 2 methods can be implemented:

1) Using WHO default values for baseline incidence and relative risk (with 95\% confidence intervals). By running the program, these values are automatically displayed.

2) Replacing the default values with estimates of baseline incidence and relative risk (95\% confidence intervals) using national and regional epidemiological studies. Because, there is a great difference between Iran and Europe with regard to the age pyramid and the software's own default data are based on the European community, it cannot be used. Therefore by reviewing the relevant texts $[9,10]$, we used the incidence and relative risks calculated for Iran. Tables 1-6 below demonstrate the results related to quantifying the health effects. 
Table 1. Estimate of relative risk indicators, component, and cases attributed to $\mathrm{PM}_{10}$ for emergency admissions to hospitals due to cardiovascular disease in Tehran (BI=436 for every 100000 persons).

\begin{tabular}{|c|c|c|c|c|c|c|}
\hline \multicolumn{7}{|c|}{ Relative Risk (RR) as per every $10 \mu \mathrm{g} / \mathrm{m}^{3}$} \\
\hline \multicolumn{7}{|c|}{ Estimate indicator } \\
\hline & Upper limit & & Central limit & & Lower limit & \\
\hline & 1.013 & & 1.009 & & 1.006 & \\
\hline $\begin{array}{l}\text { Number of attrib- } \\
\text { uted cases } \\
\text { (Person) }\end{array}$ & $\begin{array}{l}\text { Atributed com- } \\
\text { ponent estimate } \\
\text { (\%) }\end{array}$ & $\begin{array}{l}\text { Number of at- } \\
\text { tributed cases } \\
\text { (Person) }\end{array}$ & $\begin{array}{c}\text { Atributed } \\
\text { component } \\
\text { estimate (\%) }\end{array}$ & $\begin{array}{l}\text { Number of at- } \\
\text { tributed cases } \\
\text { (Person) }\end{array}$ & $\begin{array}{c}\text { Atributed } \\
\text { component } \\
\text { estimate (\%) }\end{array}$ & Year \\
\hline 2539 & 7.19 & 1797.5 & 5.09 & 1219.1 & 3.45 & 2005 \\
\hline 1820.5 & 5.02 & 1280.1 & 3.53 & 863.6 & 2.38 & 2006 \\
\hline 2497.6 & 6.79 & 1766 & 4.8 & 1196.5 & 3.25 & 2007 \\
\hline 2794.9 & 7.49 & 1980.6 & 5.31 & 1344.2 & 3.6 & 2008 \\
\hline 3004.5 & 7.94 & 2132.2 & 5.63 & 1448.7 & 3.82 & 2009 \\
\hline 3786.6 & 9.86 & 2703.6 & 7.04 & 1845.7 & 4.81 & 2010 \\
\hline 3360 & 8.63 & 2389.6 & 6.13 & 1626.4 & 4.17 & 2011 \\
\hline 3504.2 & 8.87 & 2494.1 & 6.31 & 1698.5 & 4.30 & 2012 \\
\hline 3044.4 & 7.6 & 2158.1 & 5.38 & 1465.1 & 3.65 & 2013 \\
\hline 3228.4 & 7.94 & 2291.1 & 5.63 & 1556.7 & 3.83 & 2014 \\
\hline 29576 & & 20990 & & 14260 & & 2005-2014 \\
\hline
\end{tabular}

Table 2. Estimate of relative risk indicators, component, and cases attributed to $\mathrm{PM}_{10}$ for emergency admissions to hospitals in Tehran due to respiratory illness (BI=1260 for every 100000 persons).

\begin{tabular}{|c|c|c|c|c|c|c|}
\hline \multicolumn{7}{|c|}{ Relative Risk (RR) for every $10 \mu \mathrm{g} / \mathrm{m}^{3}$} \\
\hline \multicolumn{7}{|c|}{ Estimate indicator } \\
\hline & Upper limit & & Central limit & & Lower limit & \\
\hline $\begin{array}{l}\text { Number of attrib- } \\
\text { uted cases } \\
\text { (Person) }\end{array}$ & $\begin{array}{c}\text { Atributed } \\
\text { component } \\
\text { estimate (\%) }\end{array}$ & $\begin{array}{l}\text { Number of at- } \\
\text { tributed cases } \\
\text { (Person) }\end{array}$ & $\begin{array}{l}\text { Atributed } \\
\text { component } \\
\text { estimate (\%) }\end{array}$ & $\begin{array}{l}\text { Number of at- } \\
\text { tributed cases } \\
\text { (Person) }\end{array}$ & $\begin{array}{c}\text { Atributed } \\
\text { component } \\
\text { estimate (\%) }\end{array}$ & Year \\
\hline 6385.1 & 6.25 & 4643.8 & 4.55 & 2838 & 2.78 & 2005 \\
\hline 4564.3 & 4.35 & 3301.3 & 3.15 & 2006.1 & 1.91 & 2006 \\
\hline 6277.5 & 5.9 & 4650.9 & 4.29 & 2784.4 & 2.62 & 2007 \\
\hline 7031.5 & 6.52 & 5117.9 & 4.74 & 3130.2 & 2.9 & 2008 \\
\hline 7563.8 & 6.91 & 5511.7 & 5.04 & 3375.1 & 3.08 & 2009 \\
\hline 9558.4 & 8.61 & 6999.8 & 6.31 & 4308.7 & 3.88 & 2010 \\
\hline 8466.9 & 7.52 & 6180.7 & 5.49 & 3791.7 & 3.37 & 2011 \\
\hline 8833.2 & 7.74 & 6452.1 & 5.65 & 3960.9 & 3.47 & 2012 \\
\hline 7660.4 & 6.61 & 5577.2 & 4.81 & 3412.1 & 2.94 & 2013 \\
\hline 8127.5 & 6.92 & 5922.5 & 5.04 & 3626.7 & 3.08 & 2014 \\
\hline 74464 & & 54352 & & 33230 & & $2005-2014$ \\
\hline
\end{tabular}

Emergencies and |D]isasters [Oluarterly 
Table 3. Estimate of relative risk indicators, component, and cases attributed to $\mathrm{SO}_{2}$ for emergency admissions to hospitals of Tehran due to acute myocardial infarction $\left(\mathrm{BI}=132\right.$ for every $\left.10 \mu \mathrm{g} / \mathrm{m}^{3}\right)$.

\begin{tabular}{|c|c|c|c|c|c|c|}
\hline \multicolumn{7}{|c|}{ Relative Risk Indicator for every $10 \mu \mathrm{g} / \mathrm{m}^{3}$} \\
\hline & Upper limit & & Central limit & & Lower limit & \\
\hline & 1.0101 & & 1.0064 & & 1.0026 & \\
\hline $\begin{array}{l}\text { Number of attrib- } \\
\text { uted cases } \\
\text { (person) }\end{array}$ & $\begin{array}{l}\text { Atributed com- } \\
\text { ponent estimate } \\
\text { (\%) }\end{array}$ & $\begin{array}{c}\text { Number of } \\
\text { attributed } \\
\text { cases } \\
\text { (person) }\end{array}$ & $\begin{array}{c}\text { Atributed } \\
\text { component } \\
\text { estimate (\%) }\end{array}$ & $\begin{array}{l}\text { Number of at- } \\
\text { tributed cases } \\
\text { (person) }\end{array}$ & $\begin{array}{l}\text { Atributed } \\
\text { component } \\
\text { estimate (\%) }\end{array}$ & Year \\
\hline 356.1 & 3.33 & 228.5 & 2.13 & 94 & 0.87 & 2005 \\
\hline 733.6 & 6.68 & 476.5 & 4.34 & 198.7 & 1.81 & 2006 \\
\hline 840.9 & 7.55 & 548 & 4.92 & 229.3 & 2.06 & 2007 \\
\hline 345.5 & 3.06 & 221.4 & 1.96 & 91 & 0.80 & 2008 \\
\hline 794.4 & 6.91 & 516.5 & 4.49 & 215.6 & 1.87 & 2009 \\
\hline 418.8 & 3.6 & 268.9 & 2.31 & 110.8 & 0.95 & 2010 \\
\hline 561.4 & 4.76 & 362 & 3.07 & 149.8 & 1.27 & 2011 \\
\hline 484.6 & 4.05 & 311.7 & 2.6 & 128.6 & 1.07 & 2012 \\
\hline 362.5 & 2.98 & 232.2 & 1.91 & 95.4 & 0.78 & 2013 \\
\hline 352.6 & $2 / 86$ & 225.8 & 1.83 & 92.7 & 0.75 & 2014 \\
\hline 5245 & & 3478 & & 1401 & & 2005-2014 \\
\hline
\end{tabular}

Table 4. Estimate of relative risk, component, and cases attributed to $\mathrm{SO}_{2}$ for emergency admissions to hospitals due to chronic obstructive pulmonary disease $\left(\mathrm{BI}=101.4\right.$ for every $\left.10 \mu \mathrm{g} / \mathrm{m}^{3}\right)$.

\begin{tabular}{|c|c|c|c|c|c|c|}
\hline \multicolumn{4}{|c|}{ Indicator } & \multicolumn{3}{|c|}{ Relative Risk (RR) for every $10 \mu \mathrm{g} / \mathrm{m}^{3}$} \\
\hline & Upper limit & & Central limit & & Lower limit & \\
\hline & 1.011 & & 1.0044 & & 1 & \\
\hline $\begin{array}{l}\text { Number of attrib- } \\
\text { uted cases } \\
\text { (Person) }\end{array}$ & $\begin{array}{c}\text { Atributed com- } \\
\text { ponent estimate } \\
\text { (\%) }\end{array}$ & $\begin{array}{c}\text { Number of } \\
\text { attributed } \\
\text { cases } \\
\text { (Person) }\end{array}$ & $\begin{array}{c}\text { Atributed } \\
\text { component } \\
\text { estimate (\%) }\end{array}$ & $\begin{array}{l}\text { Number of at- } \\
\text { tributed cases } \\
\text { (Person) }\end{array}$ & $\begin{array}{c}\text { Atributed } \\
\text { component } \\
\text { estimate (\%) }\end{array}$ & Year \\
\hline 297.1 & 3.61 & 121.5 & 1.47 & 0 & 0 & 2005 \\
\hline 610.1 & 7.23 & 255.1 & 3.02 & 0 & 0 & 2006 \\
\hline 698.8 & 8.17 & 293.9 & 3.46 & 0 & 0 & 2007 \\
\hline 288.3 & 3.32 & 117.7 & 1.35 & 0 & 0 & 2008 \\
\hline 660.5 & 7.48 & 276.6 & 3.13 & 0 & 0 & 2009 \\
\hline 349.3 & 3.91 & 143.1 & 1.6 & 0 & 0 & 2010 \\
\hline 467.7 & 5.16 & 193 & 2.13 & 0 & 0 & 2011 \\
\hline 403.9 & 4.39 & 166 & 1.8 & 0 & 0 & 2012 \\
\hline 302.5 & 3.24 & 123.4 & 1.32 & 0 & 0 & 2013 \\
\hline 294.3 & 3.11 & 119.9 & 1.26 & 0 & 0 & 2014 \\
\hline 3980 & & 1806 & & 0 & & 2005-2014 \\
\hline
\end{tabular}


Table 5. Estimate of relative risk, component, and cases attributed to $\mathrm{NO}_{2}$ for emergency admissions to hospitals in Tehran due to chronic obstructive pulmonary disease $\left(\mathrm{BI}=101.4\right.$ for every $\left.10 \mu \mathrm{g} / \mathrm{m}^{3}\right)$.

\begin{tabular}{|c|c|c|c|c|c|c|}
\hline \multicolumn{4}{|c|}{ Indicator } & \multicolumn{3}{|c|}{ Relative Risk (RR) for every $10 \mu \mathrm{g} / \mathrm{m}^{3}$} \\
\hline & Upper limit & & Central limit & & Lower limit & \\
\hline & 1.0044 & & 1.0026 & & 1.006 & \\
\hline $\begin{array}{l}\text { Number of attrib- } \\
\text { uted cases } \\
\text { (Person) }\end{array}$ & $\begin{array}{l}\text { Atributed com- } \\
\text { ponent estimate } \\
\text { (\%) }\end{array}$ & $\begin{array}{l}\text { Number of } \\
\text { attributed } \\
\text { cases } \\
\text { (Person) }\end{array}$ & $\begin{array}{c}\text { Atributed } \\
\text { component } \\
\text { estimate (\%) }\end{array}$ & $\begin{array}{l}\text { Number of at- } \\
\text { tributed cases } \\
\text { (Person) }\end{array}$ & $\begin{array}{c}\text { Atributed } \\
\text { component } \\
\text { estimate (\%) }\end{array}$ & Year \\
\hline 297.9 & 3.62 & 178.7 & 2.17 & 41.9 & 0.51 & 2005 \\
\hline 353.8 & 4.19 & 212.7 & 2.52 & 50.1 & 0.59 & 2006 \\
\hline 566.8 & 6.62 & 344.3 & 4.02 & 82 & 0.95 & 2007 \\
\hline 655.3 & 7.55 & 399.6 & 4.6 & 95.6 & 1.10 & 2008 \\
\hline 427.5 & 4.85 & 257.7 & 2.92 & 60.8 & 0.69 & 2009 \\
\hline 456.7 & 5.11 & 275.7 & 3.08 & 65.2 & 0.73 & 2010 \\
\hline 318.2 & 3.51 & 190.7 & 2.10 & 44.7 & 0.49 & 2011 \\
\hline 297.9 & 3.24 & 178.4 & 1.94 & 41.8 & 0.45 & 2012 \\
\hline 359.6 & 3.85 & 215.9 & 2.31 & 50.7 & 0.54 & 2013 \\
\hline 344.6 & 3.64 & 206.7 & 2.18 & 48.5 & 0.51 & 2014 \\
\hline 3972 & & 2454 & & 576 & & $2005-2014$ \\
\hline
\end{tabular}

Table 6. Estimate of relative risk indicators, component, and cases attributed to $\mathrm{O}_{3}$ for emergency admissions to hospitals in Tehran due to chronic obstructive pulmonary disease $\left(\mathrm{BI}=101.4\right.$ for every $\left.10 \mu \mathrm{g} / \mathrm{m}^{3}\right)$.

\begin{tabular}{|c|c|c|c|c|c|c|}
\hline \multicolumn{3}{|c|}{ Indicator } & \multicolumn{4}{|c|}{ Relative Risk (RR) for every $10 \mu \mathrm{g} / \mathrm{m}^{3}$} \\
\hline & Upper limit & & Central limit & & Lower limit & \\
\hline & 1.013 & & 1.009 & & 1.006 & \\
\hline $\begin{array}{l}\text { Number of } \\
\text { attributed cases } \\
\text { (Person) }\end{array}$ & $\begin{array}{c}\text { Atributed } \\
\text { component } \\
\text { estimate (\%) }\end{array}$ & $\begin{array}{c}\text { Number of } \\
\text { attributed } \\
\text { cases } \\
\text { (Person) }\end{array}$ & $\begin{array}{c}\text { Atributed } \\
\text { componentestimate } \\
\text { (\%) }\end{array}$ & $\begin{array}{l}\text { Number of } \\
\text { attributed } \\
\text { cases } \\
\text { (Person) }\end{array}$ & $\begin{array}{c}\text { Atributed } \\
\text { component } \\
\text { estimate (\%) }\end{array}$ & Year \\
\hline 298.1 & 3.62 & 186.5 & 2.27 & 71.8 & 0.87 & 2005 \\
\hline 425.4 & 5.04 & 286.3 & 3.39 & 149 & 1.76 & 2006 \\
\hline 453.6 & 5.3 & 285.7 & 3.34 & 110.7 & 1.29 & 2007 \\
\hline 652.6 & 7.52 & 414.6 & 4.78 & 162.1 & 1.86 & 2008 \\
\hline 596.3 & 6.77 & 377.8 & 4.29 & 147.2 & 1.67 & 2009 \\
\hline 509 & 5.7 & 321.1 & 3.59 & 124.6 & 1.39 & 2010 \\
\hline 435.7 & 4.81 & 273.9 & 3.02 & 105.9 & 1.16 & 2011 \\
\hline 447.4 & 4.87 & 281.3 & 3.06 & 108.8 & 1.18 & 2012 \\
\hline 442.5 & 4.75 & 278.1 & 2.98 & 107.5 & 1.15 & 2013 \\
\hline 383.7 & 4.06 & 240.5 & 2.54 & 92.7 & 0.98 & 2014 \\
\hline 4640 & & 2941 & & 1175 & & 2005-2014 \\
\hline
\end{tabular}




\section{Discussion}

In the present study, the number of emergency cases admitted and hospitalized due to cardiovascular and respiratory illnesses, chronic obstructive pulmonary disease, and heart attack resulting from exposure to air pollutants in the Greater Tehran metropolitan area during the recent decade was quantified and estimated by employing the AirQ model. The results of the study showed that air pollution has increased the emergency admissions of respiratory and cardiac patients to hospitals in Tehran. Quantifying the effects of air pollution, especially defines how much the people are affected by air pollutants and demonstrates better the critical condition of air quality. Establishing a direct link between the exposure to different concentrations of air pollutants and their impact on human health is very difficult.

This method is one of the most valid methods provided by the World Health Organization used for examining the health effects attributed to air pollutants. According to Tables 1 and 2, the numbers of cases attributed to $\mathrm{PM}_{10}$ for hospitalization due to cardiovascular and respiratory illnesses during the past decade have been 20990 and 54352 persons, respectively, which shows that particulate matter is responsible for more emergency admissions as compared with other causes. The studies conducted by Kosha and colleagues have also shown that there is a significant relation between the concentration of particulate matter and the number of admissions of cardiovascular and respiratory patients to the hospitals in Tabriz. They demonstrated that by increase in the concentration of particulate matter, the number of admissions of patients suffering from the above mentioned illnesses to hospitals has increased [11].

The study by Ebrahimzadeh et al. also showed that by every $110 \mu \mathrm{g}$ increase of air pollutant in a cubic meter of air, there will be an increase of $1.35 \%$ and $0.021 \%$, respectively, in the incidence of cardiac and respiratory illnesses in Sanandaj [12]. Studies by Pan et al. showed significant relationship between storms of dust and particulate matter with increase in hospital admissions [13]. According to the studies by Al-Hurban, high concentration of particulate matter in the storms of dust leads to bronchitis, asthma, and allergies [14]. Research by A. Peter et al. showed a close relationship between daily changes in particulate matter and hospital admissions and worsening of symptoms in cardiovascular patients [15].

According to Table 3, the number of emergency admissions to hospitals due to acute myocardial infarction resulting from exposure to sulfur dioxide during the past decade is 3478 patients. According to Tables 4-6, the numbers of emergency admissions in hospitals due to chronic obstructive pulmonary disease resulting from exposure to sulfur dioxide, nitrogen dioxide, and ozone are respectively, 1806, 2454, and 2941 patients.

Studies carried out in Tehran also showed that in addition to particulate matter, sulfur dioxide and nitrogen dioxide are the most important causes of death resulting from cardiac diseases in Tehran [16]. Masjedi in his study also showed that there was a significant relationship between air pollutants of sulfur dioxide and nitrogen dioxide and asthma attacks in Tehran [17]. High level of sulfur dioxide arises from failure to remove sulfur from fuel, especially diesel fuel. Regarding the issue of transportation and industries located in the city, the use of heavy fuels such as fuel oil and diesel fuel with highsulfur content has a significant role.

In another research in Australia, the most important factor for admission of patients to the emergency ward of hospitals in Brisbane City due to respiratory complications, besides particulate matter with diameter less than 10 microns, was ozone as a pollutant agent [18]. Zhong also showed that the most important factor in admission of children to hospitals is asthma attack resulting from exposure to particulate matter and ozone [19]. Based on a research conducted during 14 years in Toronto, Canada, the median annual number of hospital admissions due to chronic obstructive pulmonary disease was 8 patients, $40.4 \%$ of whom were reported as the result of exposure to nitrogen dioxide [20].

In a study done by Ghanbari et al. in Tabriz entitled "The Effect of Exposure to Nitrogen Dioxide, Ozone, and Sulfur Dioxide on Hospital Admissions Resulting From Chronic Obstructive Pulmonary Disease in the City of Tabriz" it was shown that there is a direct link between exposure to gaseous pollutant and respiratory diseases and chronic obstructive pulmonary disease in a way that in Tabriz during just 1 year, 69 patients were hospitalized due to respiratory illnesses; out of them, 32 cases suffered from chronic obstructive pulmonary disease [21]. Based on the present study results, most important air pollutant agent of the air in Tehran is the particulate matter.

To summarize, the research findings have shown a significant and positive relationship between the respiratory and cardiac patients admitted to the hospitals and air pollution in Tehran. By equipping, mobilizing, and preparing hospitals, health care centers, and other related centers, as well as specialized training and better preparation in health centers, the adverse health effects can be 
minimized at the time of air pollution. It is noteworthy that in all formulas used in AirQ model, it is supposed that estimates used in the analysis were controlled as regards to all possible confounding factors [22].

\section{Conclusion}

Increasing population has led to uncontrolled urban development and increased use of fossil fuels which are the main causes of air pollution. Generally, the number of cardiovascular and respiratory illnesses as well as the chronic obstructive pulmonary disease and heart attacks clearly indicate the impact of air pollution on the health of citizens. Therefore, proper and effective planning is needed to control and reduce the harmful impacts of air pollutants, especially the particulate matter. Results of this study and software output showed that air pollution in Tehran has increased the load of emergency admissions to hospitals as well as the incidence of respiratory and cardiac illnesses.

Therefore, the readiness and mobilization of hospitals, especially the emergency wards, are among the important priorities that should be seriously considered by the authorities. Obviously, the preparedness and mobilization of hospitals and health centers can play an effective role in reducing the adverse effects resulting from air pollution. Also, the decision-makers and authorities should employ appropriate, practical, sustainable, and enforceable resolutions based on scientific studies to reduce and control air pollution in the Greater Tehran metropolitan area.

\section{Acknowledgements}

This article was a part of aresearch plan entitled "Examining the Health Effects of Air Pollution of the metropolitan Tehran on the Number of Deaths and Cardiovascular and Respiratory Diseases and Analysis of Air Quality Indicators During 2005-2014" with code number 25455 approved by Iran University of Medical Sciences and Health and Treatment Services. This research was conducted with the support of the Deputy Dean's Office for Research of Iran University of Medical Sciences. Authors express their gratitude for the cooperation of the officials of Tehran Air Quality Control Institute and the General Office of Environmental Protection of Tehran Province with regard to collection of information.

\section{Conflict of Interests}

The authors declared no conflict of interests.

\section{References}

[1] World Health Organization. Burden of disease from Ambient air pollution for 2012. Geneva: World Health Organization; 2012.

[2] Kermani M, Dowlati M, Jonidi Ja'fari A, Rezaei Kalantari R. [Estimation of mortality, acute myocardial infarction and chronic obstructive pulmonary disease due to exposure to $\mathrm{O}_{3}$ $\mathrm{NO}_{2}$, and $\mathrm{SO}_{2}$ in ambient air in Tehran (Persian)]. Journal of Mazandaran University of Medical Sciences. 2016; 26(138):96107.

[3] Motesaddi Zarandi S, Raei Shaktaie H, Yazdani Cheratee J, Hosseinzade F, Dowlati M. [Evaluation of $\mathrm{PM}_{2.5}$ concentration and determinant parameters on its distribution in Tehran's metro system in 2012 (Persian)]. Journal of Mazandaran University of Medical Sciences. 2013; 22(2):37-46

[4] Arfaeinia H, Kermani M, Aghaei M, Bahrami Asl F, Karimzadeh $\mathrm{S}$. [Comparative investigation of health quality of air in Tehran, Isfahan and Shiraz metropolises in 2011-2012 (Persian)]. Journal of Health in the Field. 2014; 1(4):37-44.

[5] Kermani M, Dowlati M, Jonidi Ja'fari A, Rezaei Kalantari R. [A study on the comparative ilnvestigation of Air Quality Health Index (AQHI) and its application in Tehran as a megacity since 2007 to 2014 (Persian)]. Journal of Research in Environmental Health. 2016; 1(4):275-84.

[6] Dehghani M, Zamanian Z, Azadbakht P, Pakizehkho R, Hashemi H. [The correlation of Shiraz air pollutants on hospital admission due to the cardiopulmonary disease in Shiraz selected educational hospitals (Persian)]. Journal of Health in System Research. 2013; 9(8):859-68.

[7] Younusian M, Ghorbani M. [Study schemes in air pollution epidemiology (Persian)]. Journal of Iran Epidemiology Specialist. 2010; 4(5):44-52

[8] Godini H, Ejraei A, Shams Khoramabadi G, Ebrahimzadeh F, Hamze B. [The relationship between the concentration of dust and respiratory and cardiac patients admitted to hospitals in Kermanshah during the year 2010 (Persian)]. Journal of Kermanshah University of Medical Sciences. 2013; 17(7):44248 .

[9] Gholampour A, Nabizadeh R, Naseri S, Yunesian M, Taghipour H, Rastkar N, et al. Exposure and health impacts of outdoor particulate matter in two urban and industrialized areas of Tabriz, Iran. Journal of Environmental Health Sciences \& Engineering. 2014; 12:27. doi: 10.1186/2052-336X-12-27

[10] Naddafi K, Hassanvand MS, Yunesian M, Momeniha F, Nabizadeh R, Faridi S, et al. Health impact assessment of air pollution in megacity of Tehran, Iran. Journal of Environmental Health Sciences \& Engineering. 2012; 9:28. doi: $10.1186 / 1735-2746-9-28$

[11] Kosha A, Rajabi A. [The relationship between concentration of suspended particles in the air and the rate of emergency admissions to hospital in Tabriz (Persian)]. Paper Presented at: the $14^{\text {th }}$ National Conference on Environmental Health; 2010 Nov 1; Yazd, Iran.

[12] Ebrahimzadeh L, Ebrahimi S, Habibi S. [The effects of dust storm on emergency admissions for heart and respiratory diseases in the city of Sanandaj (Persian)]. Paper Presented at: the $14^{\text {th }}$ National Conference on Environmental Health; 2010 Nov 1; Yazd, Iran. 
[13] Pan X, Junhan CL. Study on health effects of dust storms in China, Seoul, Korea. Journal of Environmental Health. 2010; 408(4):26-28.

[14] Al-Hurban AE, Al Ostad AN. Textural characteristics of dust fallout and potential effect on public health in Kuwait City and suburbs. Journal of Environmental Health. 2010; 60(1):169-81.

[15] Peters A. Particulate matter and heart disease: evidence from epidemiological studies. Journal of American Thoracic Society. 2005; 207(2):477-82.

[16] Mohamadi H. [The correlation of Tehran atmospheric parameters and air pollution with heart attack mortality rate (1999-2003 study periods) (Persian)]. Journal of Geographical Research. 2006; 58(38):47-66.

[17] Masjedi MR, Jamati HR, Dokohaki P, Ahmadzadeh Z, Alinejadtaheri S, Bigdeli M, et al. Study the correlation of air pollution with acute hearth and respiratory attack. Journal of Research in Medical Science. 2001; 25(1):25-33.

[18] Chen L, Mengerson K, Tong S. Spatiotemporal relationship between particle air pollution and respiratory emergency hospital admissions in Brisbane, Australia. Science of the Total Environment. 2007; 373(1):57-67.

[19] Zhong W, Levin L, Reponen T, Hershey GK, Adhikari A, Shukla R. Analysis of short-term influences of ambient aeroallergens on pediatric asthma hospital visits. Science of the Total Environment. 2006; 370(2-3):330-36.

[20] Burnett RT, Smith-Doiron M, Stieb D, Cakmak S, Brook JR Effects of particulate and gaseous air pollution on cardiorespiratory hospitalizations. Archives of Environmental Health. 1999; 54(2):130-39.

[21] Ghanbari Ghozikali M, Heibati B, Naddafi K, Kloog I, Oliveri Conti G, Polosa R, et al. Evaluation of chronic obstructive pulmonary disease (COPD) attributed to atmospheric $\mathrm{O}_{3^{\prime}} \mathrm{NO}_{2}$, and $\mathrm{SO}_{2}$ using Air Q Model (2011-2012 year). Environmental Research. 2016; 144:99-105. doi: 10.1016/j.envres.2015.10.030

[22] United States Environmental Protection Agency. Air quality criteria for Carbon Monoxide. Washington, D.C.: United States Environmental Protection Agency Publication; 1991. 
